\title{
URBAN FOODPRINTS (UF) - ESTABLISHING BASELINE SCENARIOS FOR THE SUSTAINABILITY ASSESSMENT OF HIGH-YIELD URBAN AGRICULTURE
}

\author{
K. BENIS ${ }^{1}$, R. GASHGARI ${ }^{2}$, A. ALSAATI ${ }^{2} \&$ C. REINHART ${ }^{1}$ \\ ${ }^{1}$ Massachusetts Institute of Technology, Department of Architecture, Cambridge USA. \\ ${ }^{2}$ Center for Complex Engineering Systems, KACST, Riyadh, Saudi Arabia.
}

\begin{abstract}
Allowing for significant water savings and year-round yields, Controlled-Environment Agriculture (CEA) is oftentimes portrayed as a sustainable alternative to conventional farming, and its practice in urban areas as a food, income and employment generator is expanding worldwide. Particularly in today's fast growing cities, where economic strength is buying food security through imports, a largescale implementation of such practices should be further investigated as potential contributors - not only to food security but also to self-sufficiency - for the production of horticultural crops. However, further than quantifying the potential for food self-sufficiency of cities through urban cultivation, there is a crucial need for assessing the extent to which such scenarios are effectively more sustainable than existing supply chains. For that purpose, this paper presents the Urban Foodprints (UF) methodology, a fundamental preliminary step in the sustainability assessment of high-yield urban agriculture, consisting of collecting and integrating data on the existing supply chain, to be used as a baseline scenario in the environmental performance analysis. Through the case of Riyadh, Saudi Arabia, where harsh climatic conditions, a heavy reliance on food imports and a growing population constitute major threats to food security, the UF method is described and applied to the top four consumed horticultural crops watermelon, tomato, onion and carrot. The environmental sustainability of high-yield urban agriculture in Riyadh is subsequently assessed for tomato, as a comparison of the resulting city's current foodprint for the crop vs. a scenario of local production in CEA urban farms. Results show that urban production in high-yield greenhouses has the potential to reduce Global Warming Potential (GWP) by 9\%. However, while water savings contribute greatly to reducing irrigation-related emissions and food miles are considerably reduced, the energy needs of the greenhouses are significantly higher than the baseline. This outcome may be improved by enhancing the envelope of the farms to reduce overheating.

Keywords: baseline scenario, Controlled-Environment Agriculture (CEA), sustainability assessment, Urban Foodprint, urban food system.
\end{abstract}

\section{INTRODUCTION}

While our cities are growing at an unprecedented pace, their relationship with the environment has deeply changed, as low fossil fuel prices and sprawling transportation infrastructures have been connecting them to increasingly remote and global hinterlands. The latter have been fueling the growing resource use intensity of urban areas, which have in turn been releasing more and more waste and emissions into oceans and the atmosphere. As a result, today's cities are heavily reliant on large-scale provision of food that is traveling from further and further away before reaching the urbanites' plates. With emerging sustainability concerns, the environmental footprint of these complex food systems, including cultivation, processing and transport, has been increasingly assessed by the scientific community over the past decade [1], [2]. At the same time, as part of their sustainability agendas, cities are promoting urban food production as a means to reduce the demand for agricultural land elsewhere and shorten food miles [3]. To rate the extend of urban food production, two metrics are being used, self-sufficiency (or self-reliance) [4], [5] and food security. According to the United Nations 'food self-sufficiency is generally taken to mean the extent to which a country can 
satisfy its food needs from its own domestic production' [6]. Food security on the other hand occurs 'when all people, at all times, have physical and economic access to sufficient, safe and nutritious food that meets their dietary needs and food preferences for an active and healthy life' [7]. Food self-sufficiency is therefore a measure of national food independence whereas food security is concerned with the stability and affordability of food supply chains. The latter is thus more applicable for cities that tend to seek local self-reliance to gain economic and social benefits, including job creation, increased property values, and community empowerment [8].

Urban self-sufficiency has been investigated by several researchers. In Singapore, looking exclusively at public housing properties, researchers have assessed the country's potential for vegetables self-sufficiency through the large-scale implementation of high-yield roof-integrated farms. Their results show that a nationwide deployment of such systems could satisfy $35.5 \%$ of domestic demand [9]. In the United States, another study estimated the level of food self-sufficiency of Cleveland, as an example for a typical post-industrial North American city. The food categories that were considered were fresh fruits and vegetables, eggs, poultry, and honey. The three assessed scenarios led to overall levels of self-reliance between $4.2 \%$ and $17.7 \%$ by weight and $1.8 \%$ and $7.3 \%$ by expenditure in total food and beverage consumption, compared to the current level of $0.1 \%$ self-reliance in total food and beverage by expenditure. The authors concluded that significant levels of local self-reliance in food, the most basic need, is possible in this type of cities, which have been plagued with home foreclosures and resulting vacant land, lack of access to healthy food, hunger, and obesity especially in disadvantaged neighborhoods [4]. Similarly, various scenarios were assessed to measure the potential level of self-sufficiency for vegetables in Montréal, showing that the city could easily satisfy its entire vegetable demand, both through high-yield hydroponic roof-integrated systems, and through low-tech on-soil farming [5]. In Europe, researchers quantified the potential of rooftop vegetable production in the city of Bologna, showing that a city-wide implementation of rooftop greenhouses could satisfy $77 \%$ of local demand [10]. In Lisbon, it was estimated that, if all the available vacant land within the Metropolitan Area was used for high-yield soilless farming, $124 \%$ of the demand for vegetables could be met locally [11]. All these case studies are showing the potential of cities for self-reliance for fresh produce, under current crop yields and consumers' demand, simply by using their vacant areas.

From an environmental sustainability standpoint, some assessments have shown that increasing self-sufficiency through local production for some crops is not necessarily more sustainable than current practice. In the UK, a study showed that producing greenhouse strawberries in London may have a higher carbon footprint than importing Spanish greenhouse strawberries [12]; in Austria, researchers found that imported tomatoes from Spain and Italy have two times lower Greenhouse Gas (GHG) emissions than those produced nationally in capital-intensive heated systems [13]. Therefore, further than quantifying the potential for food self-sufficiency of cities through urban cultivation, there is a crucial need for assessing the extent to which such scenarios are more resource efficient than existing supply chains. For that purpose, a fundamental step in the sustainability assessment of alternative local food supply practices is the assessment of existing supply chains, to be used as baseline scenarios of the analysis. In this study, we will refer to these baseline scenarios as 'Urban Foodprints' (UF), a concept that has been previously used to express resource consumption and environmental impacts associated with the urban food system, from agricultural production to distribution and consumption (e.g. [14]). 
This paper is organized as follows: Section 2 synthesizes the existing literature on environmental sustainability assessment of urban CEA and identifies research gaps. Section 3 describes a new methodology to establish baseline scenarios for the sustainability assessment of urban food production followed by an application of the method to Riyadh, Saudi Arabia as a case study in section 4 .

\section{ASSESSING ENVIRONMENTAL IMPACTS OF URBAN CEA}

The role of urban agriculture - as a source of local and fresh food - in enhancing urban food security in cities has been widely recognized [15] and its commercial-scale implementation in highly populated urban areas has led to an increasing interest over the past decade [16]. By commercial urban agriculture, here we refer to high-yield food production in Controlled-Environment Agriculture (CEA) units such as Vertical Farms (VF), Rooftop Greenhouses (RG) or Shipping Container Farms (SC) as defined in a previous study [16], located within the urban built environment. Oftentimes portrayed as sustainable alternatives to conventional food production, these commercial farms are gaining momentum, both among entrepreneurs and academics. Allowing for significant water savings and year-round yields and fostered by technology developments such as highly efficient spectrum-specific grow lights and computer-assisted climate and crop control systems, the practice of CEA as a food, income and employment generator is expanding in major cities worldwide. However, while there is a large body of literature quantitatively evaluating crop growth in controlled environments such as greenhouses, the sustainability assessment of CEA facilities within urban contexts is a relatively new field of research [16].

Since Despommier's aspirational depiction of the vertical farm concept was published almost a decade ago [17], CEA farms have sprouted in several cities around the globe and several attempts have been made to quantify how CEA's overall environmental impact compares to current agricultural practices. In London, a study estimated the environmental footprint of lettuce production in a hypothetical high-rise urban vertical farm and compared it to the environmental footprint of lettuce conventionally grown in the UK in winter and summer [18]. Similarly, other authors have compared resource use intensity of CEA in cities like Barcelona, New York and Boston, to conventional cultivation facilities in respective countries, for the production of tomato and lettuce [19], [20]. While these approaches compare the environmental performance of the growing processes involved in energy-intensive CEA vs. conventional cultivation, they do not offer a complete assessment of whether indoor farming could mitigate environmental impacts of the vegetables that are currently distributed in cities. To do so, it would have been necessary to compare the footprint of the urban farms to the footprint of the existing supply chain for the vegetables, i.e. to include all the - domestic and foreign - locations of origin of the tomato and lettuce, measuring environmental impacts of respective production modes in each one of these locations, and finally considering conditioned transportation of the produce from the farms to the city.

In a recently published article, two of the authors of this study performed such an assessment, comparing high-yield production of tomatoes in conditioned urban farms in Lisbon vs. the existing supply chain for tomatoes distributed in the city [11]. Establishing the baseline scenario involved extensive data collection on all the locations from which tomatoes are being sourced, including farming practices, average yields, resource use, and food miles. Similarly, baseline scenarios were built for tomato supply in three additional cities of different sizes, located under different climate conditions and with diverse foodshed characteristics - Singapore, Paris and New York - and the environmental footprint of their current supply 
chains for tomatoes were compared to hypothetical urban rooftop-integrated conditioned greenhouses and closed shipping container farms. Whereas rooftop greenhouses were found to significantly reduce GHG emissions under all four climates, shipping container farms only yielded a positive environmental balance vis-à-vis the baseline in megacities located in colder climates, that seasonally rely on long distance food imports [21]. Whereas Despommier presented urban vertical farms as the absolute sustainable solution to the world's food supply problems, these outcomes reveal how context-specific the sustainability of urban food production is, and highlight the importance of building baseline scenarios that take into account the existing supply chain for the assessed crops in each particular urban context.

Establishing these scenarios is a data-intensive task and collecting the data can be challenging. Next section describes the UF methodology that we used to build these baselines, including major challenges and pitfalls.

\section{THE URBAN FOODPRINTS METHOD}

Defining Urban Foodprints consists of getting snapshots of the existing food system for a given urban area, using metrics related to food demand, resource use intensity of production, and food miles, to estimate the overall environmental impacts caused by the supply of a given produce to the city. The following sections describe the steps of the data collection to build the Urban Foodprint of a given crop, for a given urban area.

\subsection{System boundary and origin of produce}

The system boundary defines the phases of the process that will and will not be included in the assessment. Life cycle assessments of food products are usually conducted from cradle to farm gate, focusing on the most environmentally-harmful phase of the products' lifespan, cultivation [1]. To enable comparisons of the existing supply chain with scenarios of local food production, Urban Foodprints encompass a larger set of activities, from cradle to distribution, in such a way as to include travel distances and transportation modes from farm gate to the assessed urban area (see Fig. 1).

Data to determine the share of the supplied crop that comes from domestic production and the share that comes from imports can be found in official agriculture and trade statistics reports and websites from national departments of agriculture and trade. Within domestic production, defining the regions of the country where the crop is produced allows to calculate

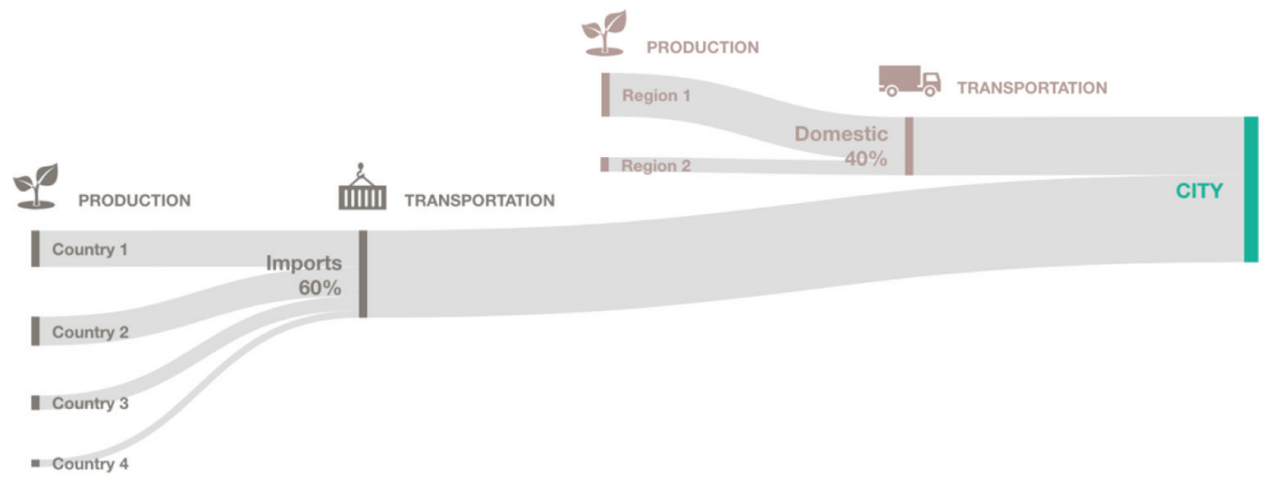

Figure 1: System boundary of the Urban Foodprints method. 
average travel distances of the crops from respective regions of origin to the city. Similarly, imported produce is disaggregated among its countries of origin, based on official trade and customs data. Food miles can subsequently be calculated as follows:

$$
F M_{A V}=\sum_{i=1}^{n} w_{i} F M_{i} \#(1)
$$

where $F M_{A V}$ (average Food Miles) is the weighted average distance travelled by the crop from its location of production to the city $(\mathrm{tkm}) ; w_{i}$ is the relative weight of each origin of supply; and $F M_{i}$ are the respective food miles travelled from each location of supply (tkm), which vary according to the food system of the city that is being assessed.

\subsection{Yields}

Furthermore, gauging to what extent high-yield urban farms can be more efficient than their conventional counterparts requires comparing respective yields, i.e. amounts of produce grown per unit of area per year in each case. For that purpose, based on the collected data on origin of produce (section 3.1), it is necessary to further investigate the dominant cultivation conditions for each location including local climate conditions, whether the crop is produced in open fields or in protected environments as well as the length of the growing season. In case the crop is produced indoors, knowing whether it is grown on-soil or through soilless cultivation techniques such as hydroponics will further inform us on the potential yields. Such information can be found in national reports, websites of national departments of agriculture, and scientific articles. Unfortunately, it can be challenging to find this information for all the regions and countries from which the crop is sourced, especially when assessing a crop whose countries of origin have a restricted or underdeveloped data infrastructure. When no data is found, assumptions have to be made, based on crops with similar growth requirements, or data from neighboring countries with similar climatic conditions and farming practices.

Once this additional data collection phase is completed, based on respective shares of origins of the assessed crop (as defined in section 3.1) and on the farming techniques that are practiced in these different locations, average yields of existing supply chains are calculated as follows:

$$
Y I E L D_{A V}=\sum_{i=1}^{n} w_{i} Y I E L D_{i} \#(2)
$$

where $Y I E L D_{A V}$ is the weighted average yield of the crop currently supplied to the city $(\mathrm{kg} /$ $\left.\mathrm{m}^{2}\right) ; w_{i}$ is the relative weight of each origin of supply; and $Y I E L D_{i}$ are the respective crop yields for each location $\left(\mathrm{kg} / \mathrm{m}^{2}\right)$, which vary according to local climatic and technological conditions in the farms.

\subsection{Resource use}

In addition to the type of farming methods practiced in different countries, UF also requires data on the amount of water use for irrigation as well as average energy use for climate control (in case of conditioned greenhouse farming) and machinery. This information may be available in national reports, websites of national departments of agriculture, and scientific 
articles. Finding this data can be challenging especially for (1) crop types that have attracted less attention within the scientific community or (2) countries for which data is generally scarce or difficult to access. Again, when no data is found, assumptions have to be made, based on crops with similar growth requirements, or data from neighbouring countries with similar climatic conditions and farming practices.

\subsection{Global warming potential}

Finally, greenhouse gas (GHG) emissions related to irrigation, operational energy and transportation of the existing supply chain of the assessed crop to the city is calculated (expressed in $\mathrm{kgCO}_{2} \mathrm{eq} / \mathrm{kg}$ ), using the relevant emission factors, as follows:

$$
G W P=\sum_{i=1}^{n} w_{i}\left(W U_{i} \times E_{i}^{I R}+E U_{i} \times E_{i}^{E L}+F_{i} \times E_{i}^{T R}\right) \#(3)
$$

where GWP is the Global Warming Potential of the crop currently supplied to the city $\left(\mathrm{kgCO}_{2} \mathrm{eq} / \mathrm{kg}\right) ; w_{i}$ is the relative weight of each origin of supply (defined in section 3.1); $W U_{i}$ is the water use per kilogram of produce $(1 / \mathrm{kg}) ; E U_{i}$ is the energy use per kilogram of produce $(\mathrm{kWh} / \mathrm{kg}) ; F_{i}$ represents the freight transport of one ton of produce over a distance of one kilometre (tkm); and $E_{i}^{I R}, E_{i}^{E L}$ and $E_{i}^{T R}$ are the respective emission factors of irrigation, electricity generation and refrigerated transportation for each origin of supply.

\section{THE RIYADH CASE-STUDY}

This section presents the application of the above laid out UF method to Saudi Arabia's capital city, Riyadh, and discusses the results.

\subsection{Background}

Today, less than $2 \%$ of land is arable in Saudi Arabia, a desert country with no permanent lakes, depleted aquifers and very little precipitation, where overgrazing and intensive agriculture are further accelerating land degradation and desertification. Surprisingly - in spite of its harsh climate and severe groundwater depletion - the kingdom produces and exports poultry, eggs, dairy products, fish, dates, fruits and vegetables. Food and water security is presently considered high as the country can rely on its oil-based economy to import most of the food and to desalinate water [22]. However, maintaining this security will be a key challenge in the coming decades due to Saudi Arabia's growing population and steady urbanization rate: the kingdom's population, 32.3 million in 2016, is expected to grow by $85 \%$ by 2050 [23] and the percentage of urbanites, $83 \%$ as of 2014 , is growing at an annual rate of $2 \%$ [22]. By 2050 , the country is expected to import practically all food from abroad [24].

Following the galloping urbanization trend, Riyadh's population has been growing steadily over the past decades - making it the most populous city in Saudi Arabia with more than 8 million residents in 2017 - and is expected to further increase by $53 \%$ by 2075 [25]. The city is located in the major agricultural region of the country, where $49 \%$ of the kingdom's vegetables are grown and occupy over half of the total national horticultural production area [26]. Major crops include tomatoes, cucumber, eggplant, onion, watermelon, squash and pumpkin, and depend heavily on irrigation, accounting for $88 \%$ of national water use in 2009 [27]. In this context of inefficiency amidst resource scarcity, the government is now promoting greenhouse cultivation and drip irrigation as more sustainable farming practices. As of 
2013, Riyadh region accounts for more than 50\% of greenhouse production of horticultural crops [26].

As mentioned above, CEA uses significantly less water than conventional farming, does not rely on arable land and is independent of ambient climatic conditions [16]. It therefore seems to be a particularly attractive technology for Saudi Arabia, where oil-based (and therefore vulnerable) economic strength is currently buying food and water security. Large-scale CEA implementation could therefore contribute not only to the country's food security but also to self-sufficiency with horticultural crops, which represent one third of the Saudi diet [28]. This case study explores to what extend CEA could contribute to Riyadh's self-sufficiency for the city's four major horticultural crops - tomatoes, carrots, watermelons and onions.

\subsection{Urban foodprints of main horticultural crops}

Figure 2 presents the UF of the four main horticultural crops supplied to the city of Riyadh, and the following subsections comment on the data collection process. Figure 3 shows the example of data collection for the urban foodprint of tomato supplied to Riyadh.

\subsubsection{Origin of produce}

Data on origin of produce were mainly collected from the statistics of the Food and Agriculture Organization of the United Nations [28] for 2013. Watermelon and tomato are among the

\begin{tabular}{|c|c|c|c|c|c|c|c|c|}
\hline & & Watermelon & Tomato & & Onion & & Carrot & \\
\hline \multirow{7}{*}{$\begin{array}{l}\text { 1. Origin } \\
\text { of produce } \\
\text { (a) }\end{array}$} & Domestic [\%] & 100 & 79 & & 25 & & 67 & \\
\hline & Imports [\%] & 0 & 21 & & 75 & & 33 & \\
\hline & & & Jordan & 11 & Egypt & 40 & Australia & 40 \\
\hline & & & Syria & 3 & Yemen & 29 & China & 29 \\
\hline & & & Egypt & 3 & India & 5 & Turkey & 5 \\
\hline & & & Turkey & 3 & & & & \\
\hline & $\begin{array}{l}\text { Avg, food miles } \\
\text { (b) }[\mathrm{km}]\end{array}$ & 1290 & 1362 & & 1642 & & 3267 & \\
\hline 2. Yields & {$[\mathrm{kg} / \mathrm{m} 2]$} & $2.2(c)$ & $5.9(f)$ & & 1.9 (a) & & $1.8(c)$ & \\
\hline \multirow[t]{2}{*}{ 3. Resources } & Water [//kg] & $449(d)$ & $104(g)$ & & $323(h)$ & & $394(g)$ & \\
\hline & Energy [kWh/kg] & $0.33(e)$ & $0.91(g)$ & & 2.50 (i) & & $1.13(g)$ & \\
\hline 4.GWP (j) & {$[\mathrm{kgCO} 2 \mathrm{eq} / \mathrm{kg}]$} & 22.74 & 6.31 & & 13.05 & & 19.71 & \\
\hline
\end{tabular}

\footnotetext{
(a) According to [28];

(b) Calculated, based on average distances between ports and then to Riyadh

(c) Calculated from [26];

(d) According to [29];

(e) Calculated from [30];
}

(f) Calculated from [24];

(g) Calculated from [31];

(h) According to [32];

(i) According to [33];

(j) Calculated from [34], [35] and [36]

Figure 2: Urban foodprints of the four main horticultural crops supplied to Riyadh. 
major horticultural crops produced in Saudi Arabia, and thus most of the produce supplied to Riyadh comes from domestic production, whereas imports are more significant for onions and carrots.

To calculate food miles, global trade routes were used as a reference. The ports with the highest activity intensities were selected. Land and sea were the main transport modes for most of the countries of origin except for Australia, where air is the main transportation mode to Saudi Arabia. Jeddah Islamic Seaport is the biggest and busiest port in the Middle East and North Africa (MENA) region. Consequently, it is considered as the main destination port for countries that ship containers to Saudi Arabia. As for land ports, Durra Border Crossing and Halat Ammar are the main ports that connect Eastern Mediterranean countries to Saudi Arabia. Approximate distances from the exporting countries to the ports were calculated, and subsequently the distances of moving the crops from the ports to Riyadh were measured. Average food miles were then estimated.

\subsubsection{Yields}

The existing literature was surveyed to determine shares of the supply produced in open fields vs. shares produced in greenhouses (see Fig. 3 for the case of tomatoes), and respective yields under each condition in respective locations of origin. While it is extremely important to find recent data that depicts as accurately as possible the current situation, for some of the cases, the most recent available data were found in studies published around a decade ago. In the meantime, diverse contextual factors such as technological improvements in greenhouse energy management or efficiency improvements in irrigation systems may have had relatively important impacts on yields.

\subsubsection{Resource use}

Estimating energy and water use is the most challenging step of establishing the foodprint of a crop, as such data are not available in FAO datasets, and has therefore to be collected from scientific articles. When no published articles for the specific crop or for its production in a

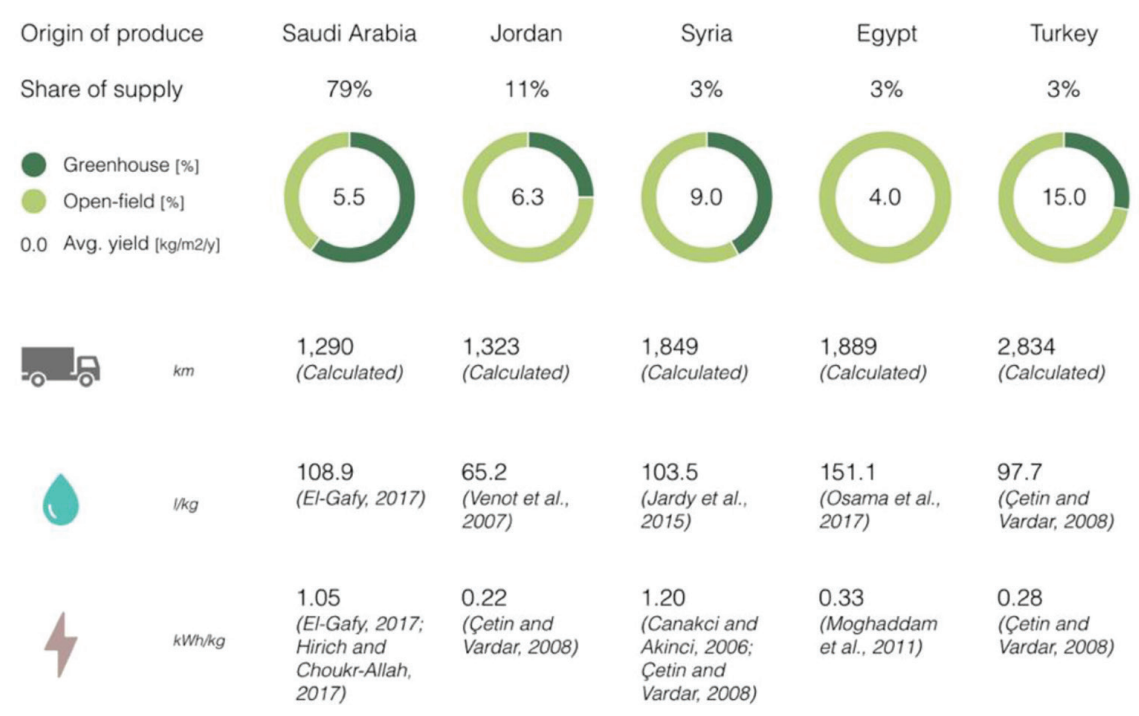

Figure 3: Urban foodprint of tomato supplied to Riyadh. 
specific country were found, data were collected for similar crops, i.e. from the same family, having similar growth requirements, or from countries with similar climatic and technological conditions.

\subsubsection{Global warming potential}

Finally, GHG emissions related to water, energy and transportation were calculated based on relevant energy mixes and emission factors.

\subsection{Comparison to local production - the case of tomato}

In an alternative scenario of urban food production in Riyadh, we focused on tomato, the crop with the lowest calculated baseline GWP (see Fig. 2), to gauge whether local production could perform better. All the fresh tomato was assumed to be produced in rooftop greenhouses within the metropolitan area, traveling an average distance of only $30 \mathrm{~km}$ to reach distribution points. A simulation workflow for crop production in urban environments - previously presented and applied to four cities [11], [21] - was applied here. Riyadh weather data were input to the model, and construction properties of the hypothetical greenhouses were defined according to the most widespread properties of existing facilities, i.e. a steel structure with a polycarbonate cover, NFT hydroponic equipment, backup lighting and an HVAC system set to maintain indoor temperatures within the optimal range for tomato growth [21]. Figure 4 synthesizes results.

Whereas commercial farming in hydroponic greenhouses can lead to efficiency gains of a factor of 8 in terms of yields and a factor of 2.7 in terms of water use, operational energy use per kilogram of produce is over four times higher in such facilities than in the baseline scenario. This is mainly due to the high cooling needs of the greenhouses under Riyadh's hot desert climate. When converting water use, operational energy and transportation to GHG emissions, results showed that urban production in high-yield greenhouses has the potential to reduce GWP by $9 \%$. While water savings contribute greatly to reducing irrigation-related emissions, the energy needs of conditioned hydroponic greenhouses are significantly higher than the baseline (where $50 \%$ of the tomatoes come from open-field cultivation, where energy requirements are drastically lower). Finally, transportation is considerably reduced. In spite

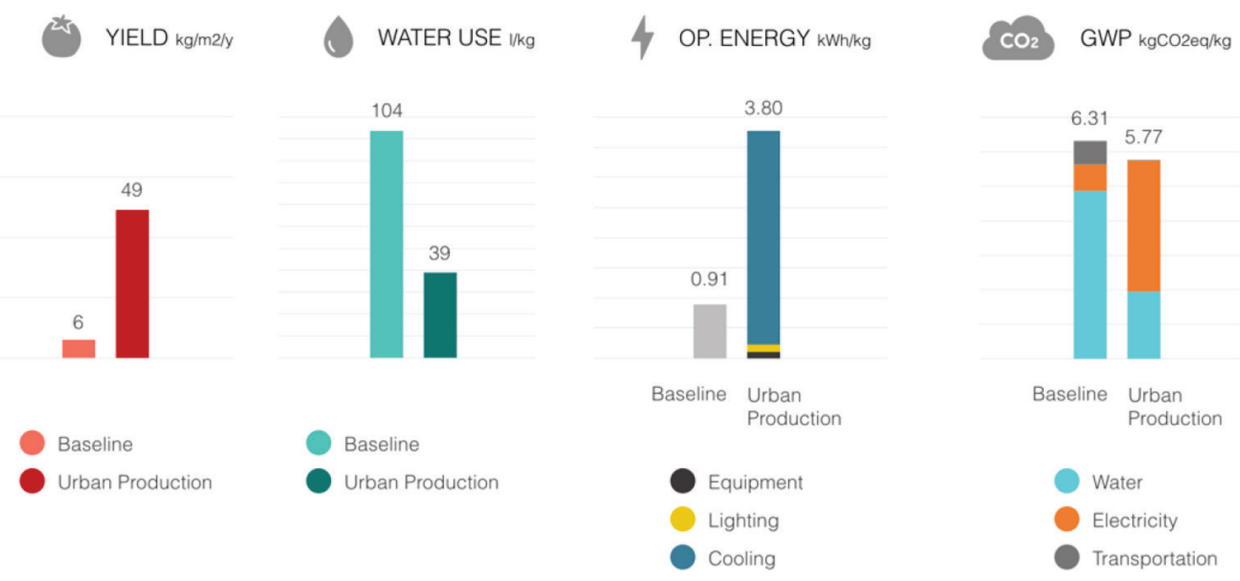

Figure 4: Baseline vs. urban production scenario. 
of the positive impact on GWP, this result is significantly below potential environmental impacts mitigations estimated for other cities, such as Lisbon - where a potential GWP reduction of 50\% was found [21] - located in a more temperate climate, where greenhouse conditioning is less energy-intensive.

\section{CONCLUSIONS}

This article described the Urban Foodprints method for the elaboration of baseline scenarios - an essential preliminary step in sustainability assessment of urban CEA scenarios. The method was applied to the city of Riyadh, Saudi Arabia. The main obstacles and challenges that were encountered throughout the data collection process were mentioned, being mainly related to the scarcity of reference sources, or, when data were not available, to accuracy in the process of making assumptions. In fact, while establishing a baseline scenario is crucial for any sustainability assessment, up-to-date and consistent data on food systems can be extremely challenging to find, as it was the case for some of the crops supplied to Riyadh. Yet even when no data are available, when thoroughly completed with grounded assumptions, UF can provide a close approximation to the baseline situation and therefore constitute a reliable starting point for sustainability assessments of urban food production scenarios.

\section{ACKNOWLEDGEMENTS}

Generous support for this work has been provided by the King Abdulaziz City for Science and Technology (KACST) as part of the research under the Center for Complex Engineering Systems (CCES) at MIT and KACST through the Urban Water, Energy and Food project.

\section{REFERENCES}

[1] Benis, K. \& Ferrão, P., Potential mitigation of the environmental impacts of food systems through Urban and Periurban Agriculture (UPA) - A life cycle assessment approach. Journal of Cleaner Production, 140(2), pp. 784-795, 2017. https://doi.org/10.1016/j. jclepro.2016.05.176

[2] Notarnicola, B., Tassielli, G., Renzulli, P.A., 3Castellani, V. \& Sala, S., Environmental impacts of food consumption in Europe. Journal of Cleaner Production, 140(2), pp. 753-765, 2017.

[3] Baker, L. \& de Zeeuw, H., Urban food policies and programmes. In Cities and Agriculture: Developing Resilient Urban Food Systems, eds. H. de Zeeuw \& P. Dreschel, Earthscan from Routledge, pp. 26-55, 2015.

[4] Grewal, S.S. \& Grewal, P.S., Can cities become self-reliant in food? Cities, 29(1), pp. 1-11, 2012. https://doi.org/10.1016/j.cities.2011.06.003

[5] Haberman, D., Gillies, L., Canter, A., Rinner, V., Pancrazi, L. \& Martellozzo, F., The potential of urban agriculture in Montreal: a quantitative assessment. ISPRS International Journal of Geo-Information, 3(3), pp. 1101-1117, 2014. https://doi.org/10.3390/ ijgi3031101

[6] Thomson, A. \& Metz, M., Implications of Economic Policy for Food Security: A Training Manual, Food and Agriculture Organization of the United Nations: Rome, 1998.

[7] Rome Declaration on World Food Security and World Summit Plan of Action, Food and Agriculture Organization of the United Nations, November 1996, Rome, Italy. http:// www.fao.org/docrep/003/w3613e/w3613e00.HTM (accessed on 11 June, 2018).

[8] Mok, H.F., Williamson, V.G., Grove, J.R., Burry, K., Barker, S.F. \& Hamilton, A.J., Strawberry fields forever? Urban agriculture in developed countries: A review. 
Agronomy for Sustainable Development, 34(1), pp. 21-43, 2014. https://doi.org/ 10.1007/s13593-013-0156-7

[9] Astee, L.Y. \& Kishnani, N.T., Building-Integrated Agriculture: Utilising rooftops for sustainable food crop cultivation in Singapore. Journal of Green Building, 5(2), pp. 105-113, 2010. https://doi.org/10.3992/jgb.5.2.105

[10] Orsini, F., Gasperi, D., Marchetti, L., Piovene, C., Draghetti, S., Ramazzotti, S., Bazzocchi, G. \& Gianquito, G., Exploring the production capacity of rooftop gardens (RTGs) in urban agriculture: the potential impact on food and nutrition security, biodiversity and other ecosystem services in the city of Bologna. Food Security, 6(6), pp. 781-792, 2014. https://doi.org/10.1007/s12571-014-0389-6

[11] Benis, K., Reinhart, C. \& Ferrão, P., Development of a simulation-based decision support workflow for the implementation of Building-Integrated Agriculture (BIA) in urban contexts. Journal of Cleaner Production, 147, pp. 589-602, 2017. https://doi. org/10.1016/j.jclepro.2017.01.130

[12] Kulak, M., Graves, A. \& Chatterton, J., Reducing greenhouse gas emissions with urban agriculture: A life cycle assessment perspective. Landscape and urban planning, 111, pp. 68-78, 2013. https://doi.org/10.1016/j.landurbplan.2012.11.007

[13] Theurl, M.C., Haberl, H., Erb, K.-H. \& Lindenthal, T., Contrasted greenhouse gas emissions from local versus long-range tomato production. Agronomy for Sustainable Development, 34(3), pp. 593-602, 2013. https://doi.org/10.1007/s13593-013-0171-8

[14] Goldstein, B., Birkved, M., Fernandez, J. \& Hauschild, M., Surveying the environmental footprint of urban food consumption. Journal of Industrial Ecology, 21(1), pp. 151165, 2016. https://doi.org/10.1111/jiec.12384

[15] Eigenbrod, C. \& Gruda, N., Urban vegetable for food security in cities. A review. Agronomy for Sustainable Development, 35(2), pp. 483-498, 2014. https://doi.org/10.1007/ s13593-014-0273-y

[16] Benis, K. \& Ferrão, P., Commercial farming within the urban built environment - Taking stock of an evolving field in northern countries. Global Food Security, 17, pp. 30-37, 2018. https://doi.org/10.1016/j.gfs.2018.03.005

[17] Despommier, D., The Vertical Farm: Feeding the world in the 21st century, Thomas Durne Books: New York, 2010.

[18] Al-Chalabi, M., Vertical farming: skyscraper sustainability? Sustainable Cities and Society, 18, pp. 74-77, 2015. https://doi.org/10.1016/j.scs.2015.06.003

[19] Sanyé-Mengual, E., Oliver-Solà, J., Montero, J.I. \& Rierdevall, J., An environmental and economic life cycle assessment of rooftop greenhouse (RTG) implementation in Barcelona, Spain. Assessing new forms of urban agriculture from the greenhouse structure to the final product level. International Journal of Life Cycle Assessment, 20(3), pp. 350-366, 2015. https://doi.org/10.1007/s11367-014-0836-9

[20] Goldstein, B., Hauschild, M., Fernandez, J. \& Birkved, M., Testing the environmental performance of urban agriculture as a food supply in northern climates. Journal of Cleaner Production, 135, pp. 984-994, 2016. https://doi.org/10.1016/j. jclepro.2016.07.004

[21] Benis, K, Reinhart, C. \& Ferrão, P., Building-Integrated Agriculture (BIA) in urban contexts: Testing a simulation-based decision support workflow. Proceedings of the 15th IBPSA Conference, pp. 1942-1951, 2017.

[22] Food and water security in the Kingdom of Saudi Arabia; Lovelle, M., Strategic Analysis Paper, Future Directions International, 28 July, 2015. http://www.futuredirections. 
org.au/publication/food-and-water-security-in-the-kingdom-of-saudi-arabia/ (accessed on 14 June, 2018).

[23] Saudi Arabia in World Population Ageing 1950-2050; United Nations, Population Division, DESA, pp. 402-403, 2016. http://www.un.org/esa/population/publications/ worldageing 19502050/pdf/177saudi.pdf (accessed on 14 June, 2018).

[24] Fiaz, S., Noor, M.A. \& Aldosri, F.O., Achieving food security in the Kingdom of Saudi Arabia through innovation: Potential role of agricultural extension. Journal of the Saudi Society of Agricultural Sciences, article in press, 2016. https://doi.org/10.1016/j. jssas.2016.09.001

[25] Statistical Year Book for 2017; General Authority for Statistics. https://www.stats.gov. sa/en/930 (accessed on 4 July, 2018).

[26] Statistical Year Book for 2013; General Authority for Statistics. https://www.stats.gov. sa/en/46 (accessed on 15 June, 2018).

[27] Irrigation in the Middle East region in figures, AQUASTAT Survey 2008, FAO, 2009. http://www.fao.org/docrep/012/i0936e/i0936e00.htm (accessed on 14 June, 2018).

[28] Agricultural statistics database of the Food and Agriculture Organization of the United Nations, FAOSTAT, 2013. http://www.fao.org/faostat/en/\#data (accessed on 15 June, 2018).

[29] Policy Options for Reducing Water for Agriculture in Saudi Arabia, KAPSARC, 2016. https://www.kapsarc.org/wp-content/uploads/2016/04/KS-1630-DP024A-PolicyOptions-for-Reducing-Water-for-Agriculture-in-SA.pdf (accessed on 15 June, 2018).

[30] Moradi, R., Moghaddam, P.R. \& Mansoori, H., Energy use and economical analysis of seedy watermelon production for different irrigation systems in Iran. Energy Reports, 1, pp. 36-42, 2015. https://doi.org/10.1016/j.egyr.2014.10.002

[31] El-Gafy, I., Water-food-energy nexus index: analysis of water-energy-food nexus of crop's production system applying the indicators approach. Applied Water Science, 7(6), pp. 2857-2868, 2017. https://doi.org/10.1007/s13201-017-0551-3

[32] Mahmoud, M.A. \& El-Baby, A.Z., Crop water requirements and irrigation efficiencies in Egypt. In The Handbook of Environmental Chemistry, Springer, Berlin, Heidelberg, 2017.

[33] Allali, K., Dhehibi, B., Kassam, S. \& Aw-Hassan, A.A., Energy consumption in onion and potato production within the Province of El Hajeb (Morocco): towards energy use efficiency in commercialized vegetable production. Journal of Agricultural Science, 9(1), pp. 118-127, 2017. https://doi.org/10.5539/jas.v9n1p118

[34] Daccache, A., Ciurana, J.S., Rodriguez Diaz, J.S. \& Knox, J.W., Water and energy footprint of irrigated agriculture in the Mediterranean region. Environmental Research Letters, 9(12), p. 124014, 2014. https://doi.org/10.1088/1748-9326/9/12/124014

[35] Brander, M., Sood, A., Wylie, C., Haughton, A. \& Lovell, J., Technical Paper: Electricity-specific emission factors for grid electricity, Econometrica, 2011. https://ecometrica.com/assets/Electricity-specific-emission-factors-for-grid-electricity.pdf (accessed on 15 June, 2018).

[36] Wang, J., Rothausen, S.G.S.A., Conway, D., Zhang, L., Xiong, W., Holman, I.P. \& Li, Y., China's water-energy nexus: greenhouse-gas emissions from groundwater use for agriculture. Environmental Research Letters, 7(1), p. 014035, 2012. https://doi. org/10.1088/1748-9326/7/1/014035 